\title{
Evaluating Software Engineering Practices IN PALESTINE
}

\author{
Mohammed Alnajjar ${ }^{1}$, Prof. Samy S. Abu Naser ${ }^{2}$ \\ ${ }^{1}$ Faculty of Information Technology, The Islamic University of Gaza, Palestine \\ ${ }^{2}$ Information Technology Department, Al-Azhar University, Gaza, Palestine
}

\begin{abstract}
Software Engineering, the art and science of building improved software, is a core requirement of the majority computer science curriculum.

Our ongoing research program focuses on three aspects of the global development of software in Palestine: (1) collection of quantitative data regarding current practice and performance in a variety of organizations; (2) determination of the adoption of competing models of software development across the organizations, and (3) analysis of the impact of different development practices on performance.

This paper show the results of a survey of software development projects principally centered in using software engineering principles.

The aim of this research is to measure the effectiveness of using software engineering practices on the productivity and quality of the software. The study showed the variation of using these practices from doing project management, requirements gathering methods, documentations, coding standard and testing. And try to give some directions to enhance the quality and productivity of the software in Palestine.

The conclusion of the survey was the majority of IT companies and organizations in Palestine did not use most of common software engineering practices as required, the usage of software standards varied among them, as most of them did not document their projects, and the testing process was negative.
\end{abstract}

\section{KEYWORDS}

Software engineering, software practices, software development methodology.

\section{INTRODUCTION}

Software engineering practices are the activities in software development process that contributes toward the satisfaction of the project goals, Software development practices are: Requirements engineering, System analysis, High-level design/architecture, Low-level design, Coding, Integration, Design and code reviews, Testing, Maintenance, Project management, Configuration management $[5,6,7,8,9]$.

DOI : $10.14810 /$ ijscmc.2015.4104 
International Journal of Soft Computing, Mathematics and Control (IJSCMC), Vol.4, No. 1, February 2015

During the past few years, the software development sector in Palestine has grown very fast for several reasons as:

- Large number of graduates in programming and engineering are equipped with different skills in software development,

- All organizations are directed to use IT in their work,

- Availability of computers and internet in every home, office and organization.

Most of the used software are developed locally in Palestine, by local companies, IT units in the organizations or individuals.

Now we can see in every organization, ministry or institute there is an IT unit responsible for developing the applications to the organization, and monitoring the operation of these applications. Most of these units have a common structure including manager, analyst and programmers.

But if we take a quick look to its work practices specially in applying software engineering practices, we can feel it's neglected by most of them, in other words we rarely found the organization apply all software engineering practices and methods, for example: some of them use requirements specification documents, design analysis but do not do project planning, others do project planning but do not document the analysis process and so on. Furthermore, there is no interest in testing process by the local companies and organizations in Palestine, so we noticed that many problems occurred when release the products for use. So these factors have influence on the quality of the software, strengths and the maintenance.

The objective of this paper / survey is designed to investigate the usage of the software engineering practices by the developers in our organizations in Palestine, and measure the effect of use or negated of these practices on the quality of the software and the cost.

Several factors proved to be statistically significant at various levels: for example, the use of prototypes, customer specifications, computer-aided software engineering (CASE) tools, parallel development, recoding, project team management, testing strategies, reuse of code, module size, communication between team members, and quality of software engineers.

In particular, we found that spending more time and effort on customer specifications improved both development speed and productivity. The results also indicated that prototyping, better software engineers, a smaller team and less code rework contributed to faster development time. Finally, more time and effort spent on testing and integration had a negative effect on overall development time. Their overall results suggest that early planning and customer specifications are crucial to productivity, while "doing it right the first time" is essential for reducing development time[7].

Today, software projects still frequently run over budget and over time. The size of the problem in the industry has been significantly condensed through the application of software engineering and enhanced project management. Software engineering is currently a core module in Computer Science degrees, as well as being offered as a more dedicated degree in its own right. 
International Journal of Soft Computing, Mathematics and Control (IJSCMC), Vol.4, No. 1, February 2015

Our research has inspected the level of use that a number of different software engineering methods received from academic researchers. We have also measured relation between software engineering usage and particular outcomes such as publication rates and funding. We have discovered some resistance to applying software engineering in academia, and through the use of interviews and case studies we have examined this problem and formulated a new software development life cycle that addresses the specific needs and concerns of academic researchers.

The motivation for our study was to investigate the degree to which different types of development practices associated with particular development "models" are used across a large sample of projects, regardless of location. In particular, we were interested in assessing the penetration of different practices falling across a spectrum ranging from those associated with more traditional "waterfall-style" approaches, which tend to emphasize achieving control and discipline in development, to those that underpin more flexible, iterative models of development, which place a greater emphasis on speed and flexibility in adapting to a set of (potentially uncertain and evolving) customer requirements [4].

Our intention was to expand the analysis of these techniques, in a way that we could examine the dependencies on other contextual factors such as the type of software (e.g., systems versus applications).

\section{SURVEY}

To achieve our objectives, we conducted a survey of software development practices in Palestine; Companies participating in the survey included UNRWA Organization, IT Unit in Al-Azhar University, IT Unit in Islamic university, IT Unit in transportation ministry, some local companies, and individuals.

The main purpose was to add some quantitative analysis to the discussion over whether practices and performance levels in software development at major firms and organizations in Palestine were comparable, better, or worse to major firms in Palestine. The size of these organizations diverse from low size organization to big size organization, Size: Very Small (2 - 10 Employee), Small (10 - 30 Employee), Medium (30- 500 Employee), Large (>500 Employee), these organization classified as $50 \%$ is profit organization and $50 \%$ nonprofit organization as outlined in Fig1 and table1. 
International Journal of Soft Computing, Mathematics and Control (IJSCMC), Vol.4, No. 1, February 2015

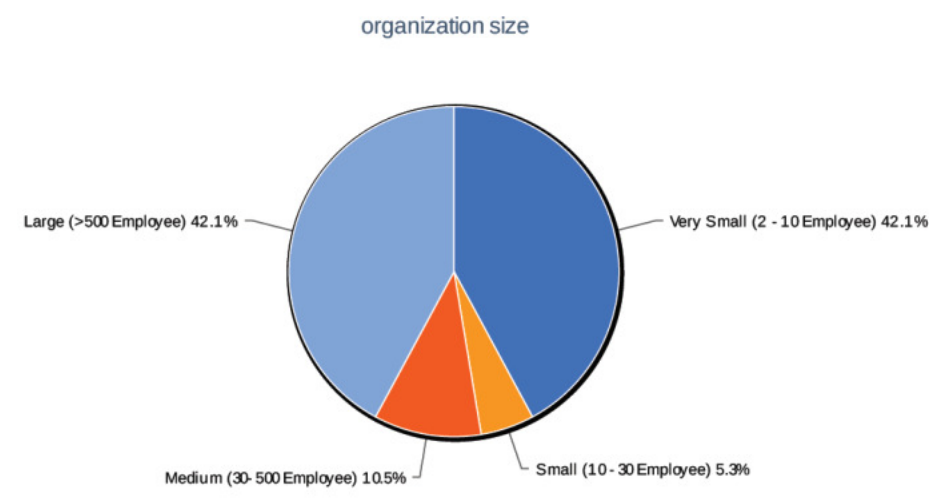

Figure 1. Participants Organizations Size

We also found that $72.2 \%$ of these organizations develop applications for its use, and $27.8 \%$ produce software to others.

Table 1: Participant Company Sizes

\begin{tabular}{|l|c|l|}
\hline \multicolumn{1}{|c|}{ Value } & Count & $\begin{array}{c}\text { Percent } \\
\%\end{array}$ \\
\hline Very Small (2 - 10 Employee) & 8 & $42.1 \%$ \\
\hline Small (10 - 30 Employee) & 1 & $5.3 \%$ \\
\hline Medium (30- 500 Employee) & 2 & $10.5 \%$ \\
\hline Large ( $>500$ Employee) & 8 & $42.1 \%$ \\
\hline
\end{tabular}

The sample covered the various responsibilities in software development process. Table 2 illustrates the distribution of the job responsibilities in the sample. However, some participants may have more than one position, most of them were programmers.

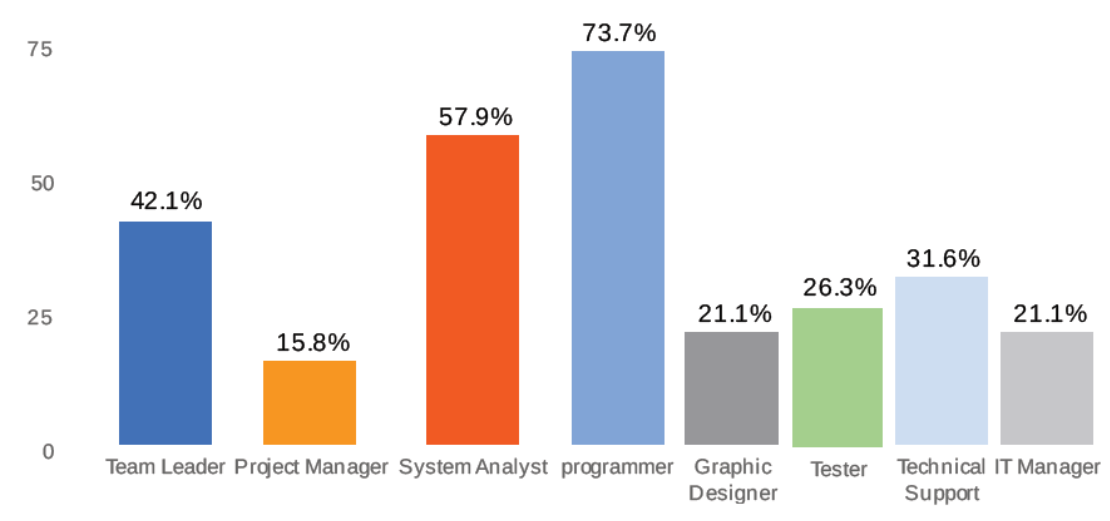

Figure 2: Participants roles Software Development process

Furthermore, the sample shows that $63.2 \%$ of the participants are responsible for other team members in their institutes. $33.2 \%$ of them are responsible for 2 employees, $33.3 \%$ of them are 
International Journal of Soft Computing, Mathematics and Control (IJSCMC), Vol.4, No. 1, February 2015 responsible for 3 employees, $11.1 \%$ of them are responsible for 7 employees, $11.1 \%$ of them are responsible for 9-12 employee, $11.1 \%$ of them are responsible for 12-15 employee.

Table 2: Participant Roles

\begin{tabular}{|c|c|c|}
\hline Value & $\begin{array}{c}\text { Cou } \\
\text { nt }\end{array}$ & $\begin{array}{c}\text { Percent } \\
\%\end{array}$ \\
\hline Team Leader & 8 & $42.1 \%$ \\
\hline Project Manager & 3 & $15.8 \%$ \\
\hline System Analyst & 11 & $57.9 \%$ \\
\hline Programmer & 14 & $73.7 \%$ \\
\hline Graphic Designer & 4 & $21.1 \%$ \\
\hline Tester & 5 & $26.3 \%$ \\
\hline $\begin{array}{c}\text { Technical } \\
\text { Support }\end{array}$ & 6 & $31.6 \%$ \\
\hline IT Manager & 4 & $21.1 \%$ \\
\hline
\end{tabular}

We found $89.5 \%$ of them works on diverse projects at the same time and $10.5 \%$ just work on a single project.

The questionnaire asked about the number of experience years in the software development. Fig. 3 and Table 3 shows the distribution of responses to this question in the sample.

experience in software development

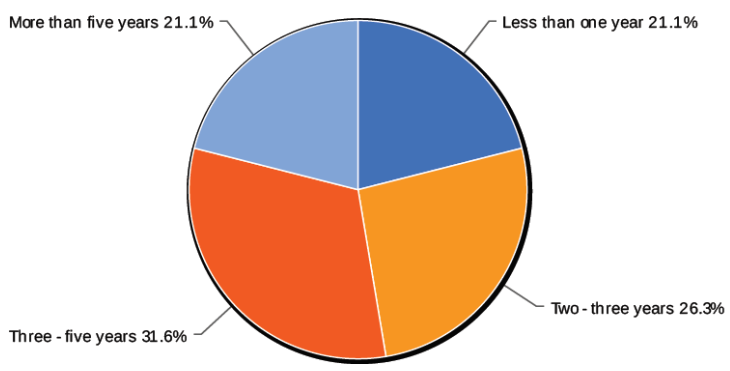

Figure 3. Participant experience years

Table 3: Participant years of experience

\begin{tabular}{|l|l|l|} 
Value & Cou & Percent \\
\hline
\end{tabular}


International Journal of Soft Computing, Mathematics and Control (IJSCMC), Vol.4, No. 1, February 2015

\begin{tabular}{|l|c|c|}
\hline & nt & \% \\
\hline Less than one year & 4 & $21.1 \%$ \\
\hline Two - three years & 5 & $26.3 \%$ \\
\hline Three - five years & 6 & $31.6 \%$ \\
\hline More than five years & 4 & $21.1 \%$ \\
\hline
\end{tabular}

We asked about the nature of the applications that they work on, there are variation among them, some of them work on developing desktop application, work on developing web applications, Mobil applications, or other applications; moreover, some of them work on more than one type of application(see Table 4).

Table 4: Types of applications

\begin{tabular}{|l|c|c|}
\hline \multicolumn{1}{|c|}{ Value } & Count & $\begin{array}{c}\text { Percent } \\
\text { \% }\end{array}$ \\
\hline Desktop applications & 14 & $73.7 \%$ \\
\hline Web applications & 13 & $68.4 \%$ \\
\hline Mobile applications & 1 & $5.3 \%$ \\
\hline Others & 2 & $10.5 \%$ \\
\hline
\end{tabular}

The survey was carried out by filling out an electronic form. The form had a total of 27 questions about the development process, divided into six parts: General information about the Participant's characteristics, Software Engineering, Specifications analysis, project planning, Implementation Standards and testing. The survey was available from $1^{\text {st }}$ of November to the $30^{\text {th }}$ of November. It was announced to software developments groups by means of discussion lists and direct email messages sent to professionals and institutions. The parsed contents of answer Analyzed statistically using Excel.

\section{SURVEY RESULTS}

In this section we will present results of survey about using Software Engineering methods and practices in Palestine, and how it was used within computer departments in the different institutes.

Yet, in a business sense, locking a project into a particular design early may not produce the best product for a customer in a changing market.

We found that the use of early prototypes opportunities for customers to provide early feedback on the design was associated with higher output rates and lower defects, probably because projects were able to make early adjustments to this feedback (meets the customer needs).

Results reported here are based on 19 respondents, of which $50 \%$ came from companies and private institutions, $50 \%$ from not-for-profit institutions.

\subsection{Requirements Analysis:}


International Journal of Soft Computing, Mathematics and Control (IJSCMC), Vol.4, No. 1, February 2015

We designed a set of questions to check the usage of some requirements analysis activates in software development life cycle, beginning from requirements elicitation process toward producing software requirements specification document. The questions measured the usage of these activities, and the results varied among the participants.

We asked about the analysis for the developed systems before coding them, we found that $55.6 \%$ of them always do analysis before coding, and $44.4 \%$ rarely do not make analysis.

About using IEEE standards for making software requirements specification report, we found $33.3 \%$ of them always us it, $44.4 \%$ rarely use it, $22.2 \%$ do not use it.

The most important question was about using requirements elicitation techniques, we found most of them use interviews for this regard (72.2\%), Table 5 and Fig. 4 summarizes these results.

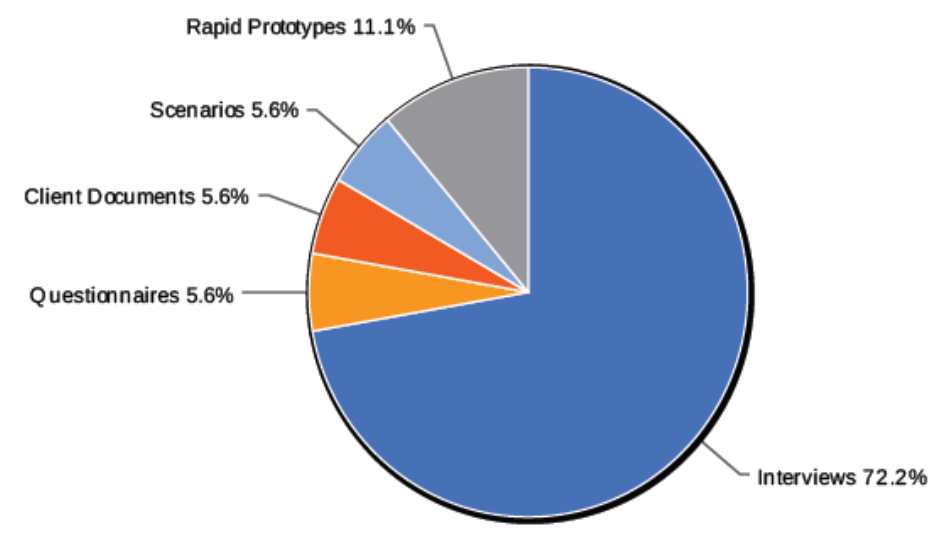

Figure 4. Requirements elicitation techniques

In case of ambiguous user needs, $89.5 \%$ of them propose prototype of the developed system and give it to the customer and then take the feedback to extract the requirements.

Table 5: Types of Requirements elicitation techniques

\begin{tabular}{|l|c|c|}
\hline \multicolumn{1}{|c|}{ Value } & Count & Percent \% \\
\hline Interviews & 13 & $72.2 \%$ \\
\hline Questionnaires & 1 & $5.6 \%$ \\
\hline Client Documents & 1 & $5.6 \%$ \\
\hline Scenarios & 1 & $5.6 \%$ \\
\hline Rapid Prototypes & 2 & $11.1 \%$ \\
\hline
\end{tabular}

About Tools Used in requirements analysis, most of them use general tools in requirements analysis process as Ms Office including Visio, and some of them use specialized tools as UML Studio and rational rows, Table 6 shows the usage percentage for every tool.

Table 6: Requirements analysis tools

\begin{tabular}{|l|l|l|} 
Value & Count & Percent \% \\
\hline
\end{tabular}


International Journal of Soft Computing, Mathematics and Control (IJSCMC), Vol.4, No. 1, February 2015

\begin{tabular}{|l|c|c|}
\hline UMLStudio & 6 & $31.6 \%$ \\
\hline Rational Rose & 5 & $26.3 \%$ \\
\hline Visio & 12 & $63.2 \%$ \\
\hline Ms Office & 12 & $63.2 \%$ \\
\hline Others & 4 & $21.1 \%$ \\
\hline
\end{tabular}

There are several software development methodologies, we asked the participants about using these methods, and we found most of them use flowchart because it's known and simple (80\%), Fig. 7 shows the usage percentage for every method.

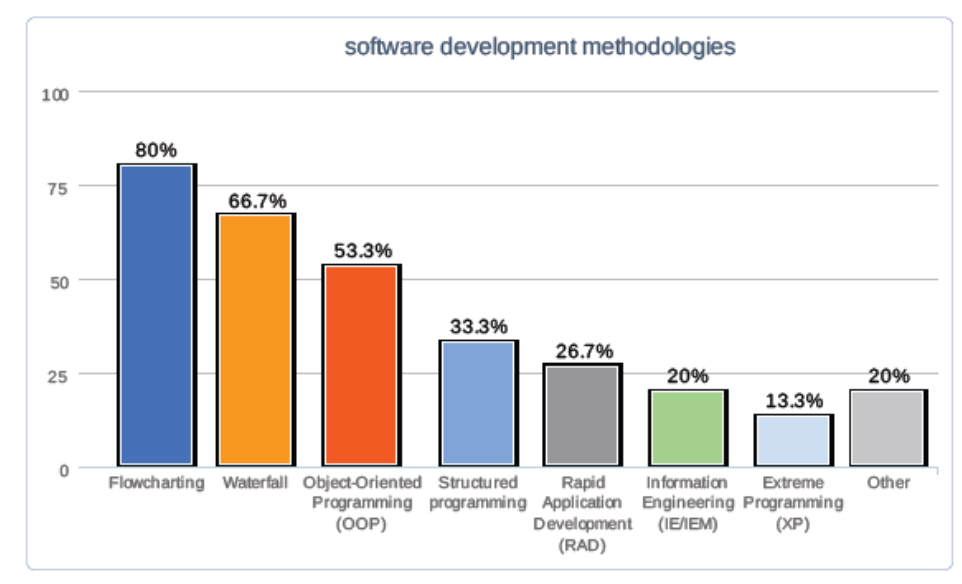

Figure 7. Requirements elicitation techniques

We investigated some issues related to requirement analysis process as, user involvement in requirement analysis process, $57.9 \%$ say that lack of user involvement in requirements process affect the speed of software production, and $55.6 \%$ of them say that Poor communication between developers and customers may be led to poorly understood requirements, poor userinterface design, $52.9 \%$ of them say that the analyst experience is essential factor in requirement analysis process to extract most of the user requirements,33.3\% of them collect all the requirements from the customer before starting the development process, $38.9 \%$ of them use standards in requirements documentation in your organization, $47.4 \%$ of them communicates with the client to get approval on the defined requirements, Table 7 shows the distribution of responses to this questions in the sample.

Table 7: Requirements analysis process

\begin{tabular}{|c|c|c|c|c|c|}
\hline Question & $\begin{array}{c}\text { Rarely } \\
(<25 \%)\end{array}$ & $\begin{array}{c}\text { Sometimes } \\
(25-49 \%)\end{array}$ & $\begin{array}{c}\text { Often } \\
(50-\end{array}$ & $\begin{array}{c}\text { Almost } \\
\text { always }\end{array}$ & $\begin{array}{c}\text { Don't } \\
\text { know } /\end{array}$ \\
\hline
\end{tabular}


International Journal of Soft Computing, Mathematics and Control (IJSCMC), Vol.4, No. 1, February 2015

\begin{tabular}{|l|c|c|c|c|c|}
\hline & & & $\mathbf{7 4 \%}$ & $\mathbf{( 7 5 \% + )}$ & N/A \\
\hline Lack of user involvement & $10.5 \%$ & $15.8 \%$ & $15.8 \%$ & $57.9 \%$ & $0.0 \%$ \\
& 2 & 3 & 3 & 11 & 0 \\
\hline $\begin{array}{l}\text { Poor communication between } \\
\text { developers and customers }\end{array}$ & $11.1 \%$ & $11.1 \%$ & $22.2 \%$ & $55.6 \%$ & $0.0 \%$ \\
\hline The analyst experience & 2 & 2 & 4 & 10 & 0 \\
\hline Collect all the requirements & $0.0 \%$ & $11.8 \%$ & $35.3 \%$ & $52.9 \%$ & $0.0 \%$ \\
before start development & $5.6 \%$ & $22.2 \%$ & $38.9 \%$ & $33.3 \%$ & $0.0 \%$ \\
\hline $\begin{array}{l}\text { Use standards in requirements } \\
\text { documentation }\end{array}$ & $16.7 \%$ & $16.7 \%$ & $27.8 \%$ & $38.9 \%$ & $0.0 \%$ \\
\hline customers change the & 3 & 3 & 5 & 7 & 0 \\
requirements after & $16.7 \%$ & $27.8 \%$ & $16.7 \%$ & $38.9 \%$ & $0.0 \%$ \\
development & 3 & 5 & 3 & 7 & 0 \\
\hline The developer communicates & $10.5 \%$ & $10.5 \%$ & $31.6 \%$ & $47.4 \%$ & $0.0 \%$ \\
with the client to get approval & 2 & 2 & 6 & 9 & 0 \\
\hline
\end{tabular}

\subsection{Project Planning:}

We designed a set of questions to check including planning activities in software development life cycle, beginning from make project planning for the developed projects toward producing software project plan document.

The questions measured the usage of these activities, and the results varied among the participants. We asked about doing analysis for the developed system before coding, we find $55.6 \%$ of them always do analysis before coding, and $44.4 \%$ rarely make any analysis.

We investigated some issues related to project planning, $33.3 \%$ of them prepare project plan report for the developed projects, and $15.8 \%$ prepare monitoring reports, $28.9 \%$ of them use time planning that allows keeping track of projects, personal tasks, and other activities, $16.7 \%$ of them make enough risk management for your projects. Table 8 shows the distribution of responses to this questions in the sample.

Table 8: Project Planning Activities

\begin{tabular}{|c|c|c|c|c|c|}
\hline Question & $\begin{array}{c}\text { Rarely } \\
(<25 \%)\end{array}$ & $\begin{array}{c}\text { Sometimes } \\
(25-49 \%)\end{array}$ & $\begin{array}{c}\text { Often } \\
(\mathbf{5 0}- \\
\mathbf{7 4 \%}\end{array}$ & $\begin{array}{c}\text { Almost } \\
\text { always } \\
(\mathbf{7 5 \%} \%)\end{array}$ & $\begin{array}{c}\text { Don't } \\
\text { know } / \\
\text { N/A }\end{array}$ \\
\hline
\end{tabular}


International Journal of Soft Computing, Mathematics and Control (IJSCMC), Vol.4, No. 1, February 2015

\begin{tabular}{|l|c|c|c|c|c|}
\hline Preparing Project plan reports & $\begin{array}{c}22.2 \% \\
4\end{array}$ & $\begin{array}{c}16.7 \% \\
3\end{array}$ & $\begin{array}{c}27.8 \% \\
5\end{array}$ & $\begin{array}{c}33.3 \% \\
6\end{array}$ & $\begin{array}{c}0.0 \% \\
0\end{array}$ \\
\hline $\begin{array}{l}\text { Preparing monitoring reports to } \\
\text { evaluate the progress. }\end{array}$ & $\begin{array}{c}4.4 \% \\
\text { Using time planning and to-do list }\end{array}$ & $\begin{array}{c}10.5 \% \\
2\end{array}$ & $\begin{array}{c}21.1 \% \\
4\end{array}$ & $\begin{array}{c}15.8 \% \\
3\end{array}$ & $\begin{array}{c}5.3 \% \\
1\end{array}$ \\
\hline software. & $22.2 \%$ & $16.7 \%$ & $22.2 \%$ & $38.9 \%$ & $0.0 \%$ \\
\hline $\begin{array}{l}\text { Needs to change Time plane according } \\
\text { to late in project development. }\end{array}$ & $33.3 \%$ & $22.2 \%$ & $27.8 \%$ & $16.7 \%$ & $0.0 \%$ \\
\hline Making enough risk management. & 6 & 4 & 5 & 3 & 0 \\
\hline $\begin{array}{l}\text { The challenges faced by someone } \\
\text { building a three-month application are } \\
\text { quite different than the challenges faced } \\
\text { by someone building a one-year }\end{array}$ & $\begin{array}{c}33.3 \% \\
\text { application. }\end{array}$ & $22.2 \%$ & $22.2 \%$ & $16.7 \%$ & $5.6 \%$ \\
\hline $\begin{array}{l}\text { Omitting necessary tasks from estimates } \\
\text { can add 20 to 30 percent to a }\end{array}$ & 4 & $26.3 \%$ & $15.8 \%$ & $36.8 \%$ & $0.0 \%$ \\
development schedule. & 5 & 3 & 7 & 0 \\
\hline
\end{tabular}

\section{3 software development methods and tools}

About Tools used in development process, we found visual studio commonly used by most of them $86.7 \%$ in Palestine, followed by Delphi $40 \%$, see Fig. 8.

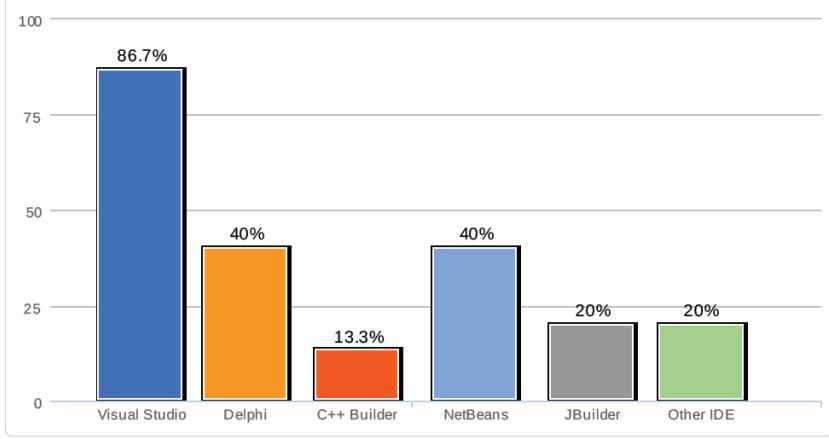

Figure 8. Development Tools

About using version control systems to share the resources of the projects among the team member, most of them use Visual SourceSafe (SVN) with percentage $46.7 \%$, but $33.3 \%$ don't use any versioning system, see table 9.

Table 9: Types Of Used versioning system

\begin{tabular}{|l|c|c|}
\hline \multicolumn{1}{|c|}{ Value } & Count & Percent \% \\
\hline Visual SourceSafe (SVN) & 7 & $46.7 \%$ \\
\hline Cvs & 2 & $13.3 \%$ \\
\hline Subversion & 2 & $13.3 \%$ \\
\hline
\end{tabular}


International Journal of Soft Computing, Mathematics and Control (IJSCMC), Vol.4, No. 1, February 2015

\begin{tabular}{|l|c|c|}
\hline $\begin{array}{l}\text { Other Open Source revision control } \\
\text { system }\end{array}$ & 1 & $6.7 \%$ \\
\hline None & 5 & $33.3 \%$ \\
\hline
\end{tabular}

About the used programming languages in development process, $\mathrm{C \#}$ is the most used language $73.3 \%$, and $60 \%$ of them use java language, see table 10 .

Table 9: Types of Used programming languages

\begin{tabular}{|l|c|c|}
\hline \multicolumn{1}{|c|}{ Value } & Count & Percent \% \\
\hline Delphi & 6 & $40 \%$ \\
\hline Java & 9 & $60 \%$ \\
\hline C\# & 11 & $73.3 \%$ \\
\hline C & 2 & $13.3 \%$ \\
\hline C++ & 3 & $20 \%$ \\
\hline PHP & 2 & $13.3 \%$ \\
\hline Asp & 6 & $40 \%$ \\
\hline Javascript / ECMAScript & 5 & $33.3 \%$ \\
\hline SQL (all variants) & 12 & $80 \%$ \\
\hline Matlab & 2 & $13.3 \%$ \\
\hline Other & 4 & $26.7 \%$ \\
\hline
\end{tabular}

$80 \%$ of them have coding standards in their organizations, $20 \%$ don't use as seen in Fig. 9.

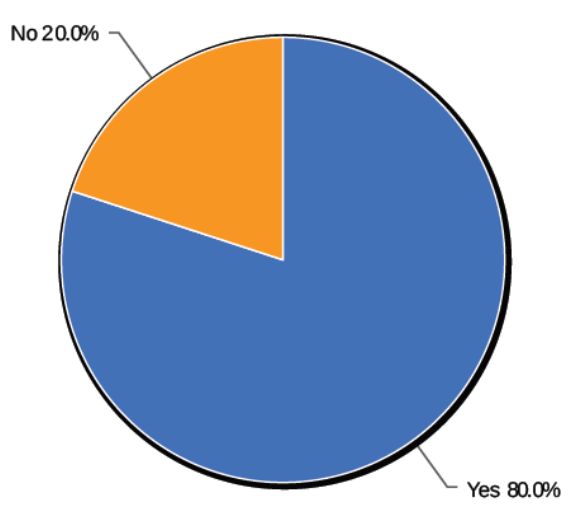

Figure 9. Using Coding Standards

\subsection{Using Testing}

Testing activities are neglected in our organizations in Palestine; we have asked some questions about using testing in software development. 
International Journal of Soft Computing, Mathematics and Control (IJSCMC), Vol.4, No. 1, February 2015

One of these questions was about having testers in IT units and the companies in Palestine responsible for testing process, $73.3 \%$ of them don't have testers in their institutes, and $26.7 \%$ have testers. But we found $100 \%$ of the developers test their code by themselves. $53.3 \%$ of them make test cases plans the in testing process.

About the type of tests that they do, most of them involved in unit testing and database testing, see the figure 10 .

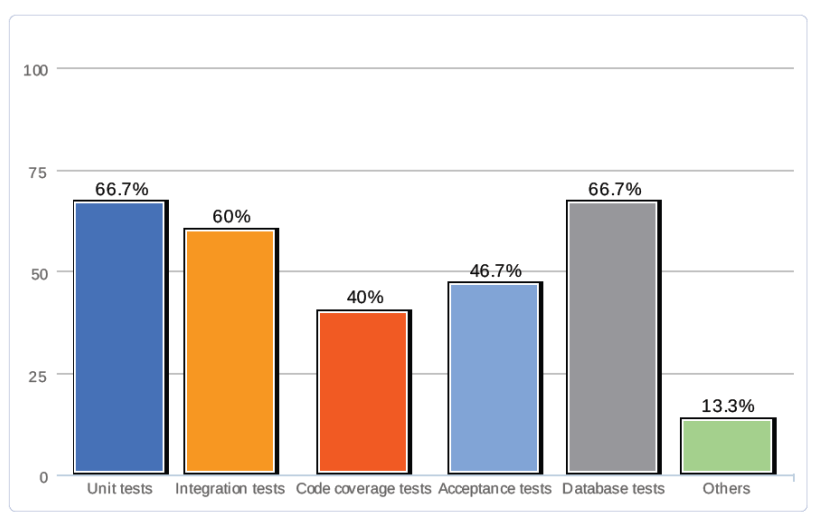

Figure 10. Used Testing Types

About using automated testing tools, some of them use it just $13.3 \%$, but $77.3 \%$ do not use automated testing tools.

\section{Conclusion}

Even though the number of collected surveys is still modest, it is adequate enough to get some conclusions about the use of software engineering methodologies in our institutions in Palestine.

We can feel that software engineering practices are neglected by most of them, in other words we seldom find the organization apply all software engineering practices and methods, and also there is no interest in testing process by the local companies and organizations in Palestine, so we noticed that lots of problems occurred when release the products for use.

So these factors have an effect on the quality of the software, strengths and the maintenance. The running applications need time to reach consistent state according to weakens in its structure or insufficient usage of software engineering practices.

\section{REFERENCES}

[1] Nuha El-Khalili , Dima Damen, "Software Engineering Practices in Jordan “. The 4th International Multi conference on Computer Science and Information Technology, Amman, Jordan, 4/4/2006

[2] Ian Sommerville, "SOFTWARE ENGINEERING- Ninth Edition", Addison-Wesley; 9 edition , 2010.

[3] Andre Oboler, "Examining the use of Software Engineering by Computer Science Researchers, 2012

[4] Dr. Laurie Williams, "Introduction to Software Engineering Practices and Methods, 2009. 
International Journal of Soft Computing, Mathematics and Control (IJSCMC), Vol.4, No. 1, February 2015

[5] Roger Pressman and Bruce Maxim Software Engineering: A Practitioner's Approach, McGraw-Hill Science/Engineering/Math; 8 edition, 2014

[6] Dr. Richard Hall Thayer and Dr. Merlin Dorfman, SOFTWARE ENGINEERING ESSENTIALS, Volume I: The Development Process, Software Management Training; Fourth edition, 2012.

[7] Eric J. Braude and Michael E. Bernstein, Software Engineering: Modern Approaches, Wiley; 2 edition, 2010

[8] Len Bass and Paul Clements Software Architecture in Practice (3rd Edition) (SEI Series in Software Engineering), Addison-Wesley Professional; 3 edition, 2012

[9] Karl Wiegers, and Joy Beatty, Software Requirements (3rd Edition) (Developer Best Practices), Microsoft Press; 3 edition, 2013 